\title{
An Elongated Tortoise (Indotestudo elongata) Attempting to Prey on a Buff-striped Keelback (Amphiesma stolatum) at the Turtle Rescue and Conservation Centre in Eastern Nepal
}

Tapil Prakash Rai

\author{
Turtle Rescue and Conservation Centre, Arjundhara Municipality-9, Jhapa, Nepal (trcc.arco@gmail.com) \\ Department of Environmental Science, Mechi Multiple Campus, Bhadrapur Municipality-8, Jhapa, Nepal (tapilprai19@gmail.com)
}

$\mathrm{T}$ he Elongated Tortoise (Indotestudo elongata) is distributed across southeastern Asia, including northern India, southern Nepal, Bhutan, and Bangladesh (Sharma 1998; Schleich and Kästle 2002; Bonin et al. 2006; Kästle et al. 2013; Ihlow et al. 2016; Uetz et al. 2019). In Nepal, it is well documented in the Terai with some records from the midlands (Schleich and Kästle 2002; Kästle et al. 2013; Kiesl and Schleich 2016; Rai 2019). Recently, the globally threatened Elongated Tortoise has been upgraded from Endangered to Critically Endangered on the IUCN Red List (Rahman et al. 2019). It is listed in CITES Appendix II (https://www.cites.org/eng/app/ appendices.php).

Elongated Tortoises inhabit a variety of forest types, including open deciduous dipterocarp, mountainous and hilly evergreen, mixed semi-evergreen, bamboo, pine, and secondary forests, as well as savannah grasslands and dry thorn scrub (Sharma 1998; Schleich and Kästle 2002; Bonin et al. 2006; Ihlow et al. 2016). In Nepal, Indotestudo elongata is typically associated with forests dominated by Sal (Shorea robusta) (Schleich and Kästle 2002; Kästle et al. 2013; Kiesl and Schleich 2016), usually in areas with high humidity and often near bodies of water (pers. obs.).

Elongated Tortoises are omnivorous generalists and the diet varies according to availability by habitat and season (Ihlow et al. 2012, 2016). It feeds on fruits, herbaceous leaves, flowers, mushrooms, grasses, vegetables, earthworms, slugs, thin-shelled terrestrial snails, worms, insects, crabs, egg shells, carrion, detritus, and the excrement of other animals (Sharma 1998; Schleich and Kästle 2002; Bonin et al. 2006; Ihlow et al. 2012, 2016; Kästle et al. 2013; Kiesl and Schleich 2016). The majority of these food items also are consumed by Elongated Tortoises (Fig. 1 ) in captivity (pers. obs.).
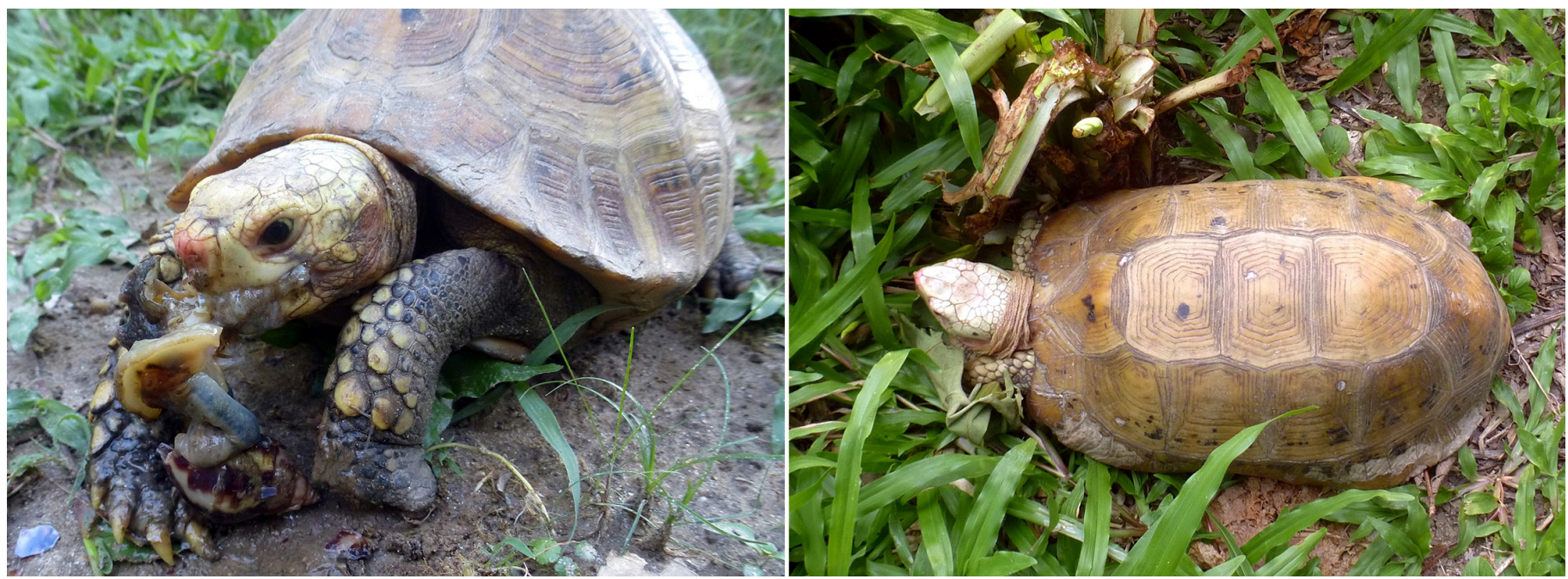

Fig. 1. Elongated Tortoises (Indotestudo elongata) at the Turtle Rescue and Conservation Centre in eastern Nepal feeding on a cracked land snail (Achatina sp.) (left) and on Taro (Colocasia sp.) (right). Photographs by Tapil Prakash Rai. 
The Turtle Rescue and Conservation Centre (TRCC) in eastern Nepal, the only community-based turtle conservation centre in Nepal, was established as a joint venture by the Amphibian and Reptile Conservation Society of Nepal (ARCO-Nepal) and Sukhani Martyrs Memorial Foundation (SUMMEF) in 2012 (Rai 2017).

Indotestudo elongata is primarily crepuscular and its activity is mainly restricted to dusk and dawn. Elongated Tortoises are most active during the rainy season when courtship and mating take place (Schleich and Kästle 2002; Kästle et al. 2013; Ihlow et al. 2016). In captivity at the TRCC, courtship has been observed from May to July (pers. obs.). Males are very aggressive during the breeding season and will fight violently with each other. During courtship, a male will persistently harass a female by biting her head and limbs and thunderously ramming her with his thick anterior plastron. This could lead to casualties, especially if the ratio of males to females is imbalanced. If a female is receptive to a male, she remains still with her tail averted to expose her cloaca. Mating typically lasts 5-7 min (pers. obs.). After mating, five male Elongated Tortoises at the TRCC were isolated. One robust young male was kept temporarily in one of the concrete pools that had been converted into a terrestrial enclosure by draining the water and lining it with leaf litter.
At $1322 \mathrm{~h}$ on 26 June 2019, an injured adult Buff-striped Keelback (Amphiesma stolatum) was discovered in the enclosure along with the male Elongated Tortoise (Fig. 2). Buffstriped Keelbacks are small $(<80 \mathrm{~cm})$, non-venomous natricid snakes that are encountered frequently in southern Nepal (Schleich and Kästle 2002; Kästle et al. 2013). This diurnal and nonaggressive snake is harmless, and when alarmed, it will quickly seek to escape. This individual must have fallen into the enclosure, where it was bitten by the tortoise more than five time, at least three of which caused considerable damage and exposed internal organs. Although Elongated Tortoises usually consume plant material or prey on invertebrates, Ihlow et al. (2016) reported feeding the carcass of a Light-barred Kukri Snake (Oligodon albocinctus) to an Elongated Tortoise in central Laos.

After the injured snake was removed from the enclosure, it was disinfected with locally available povidone-iodine and released into nearby habitat. An Elongated Tortoise preying on a live snake is herein documented for the first time.

\section{Acknowledgements}

I thank the Turtle Rescue and Conservation Centre (TRCC), Arjundhara Municipality-9, Jhapa, and Martyrs Memorial Park (SUMMEF), Jhapa, for their help in con-

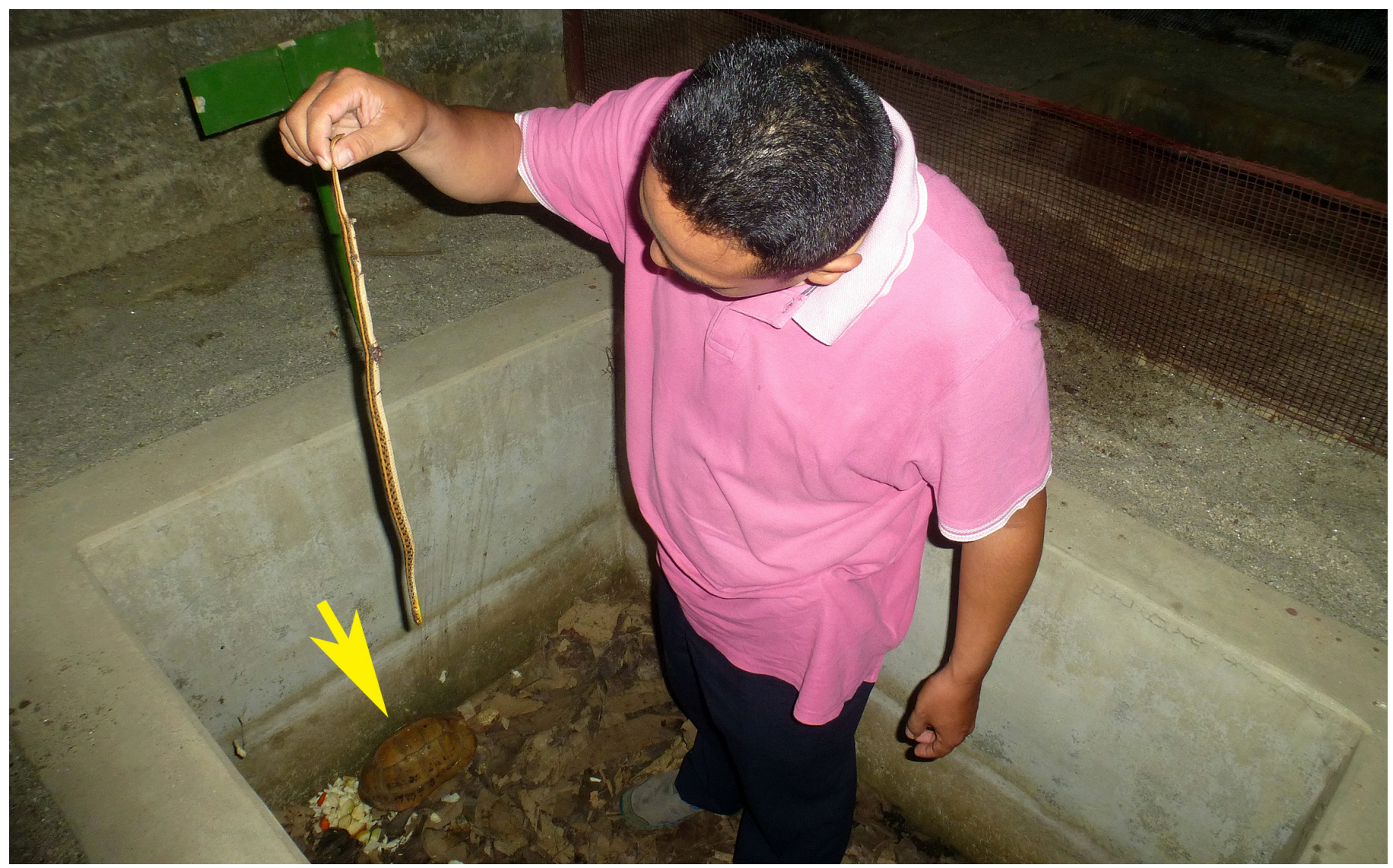

Fig. 2. A Buff-striped Keelback (Amphiesma stolatum) injured by an Elongated Tortoise (Indotestudo elongata) that had attempted to consume it at the Turtle Rescue and Conservation Centre in eastern Nepal. Note the exposed internal organs of the snake. Photograph by Sabin Adhikari. 
ducting this research. I also thank the Amphibian and Reptile Conservation Society of Nepal (ARCO-Nepal) for providing technical support. Furthermore, I am thankful to Dr. Kalu Ram Rai, Professor of Zoology, for suggestions that improved this manuscript. Finally, I acknowledge Sabin Adhikari, Nilu Phuyel, and Bhuwan Pradhan for assistance in the field.

\section{Literature Cited}

Bonin, F., B. Devaux, and A. Dupre. 2006. Turtles of the World. A \& C Black, London, United Kingdom. (Originally published in French in 1996; translated by P.C.H. Pritchard).

Ihlow, F., P. Geissler, S. Sovath, M. Handschuh, and W. Böhme. 2012. Feeding ecology of Indotestudo elongata (Blyth 1853) in the wild in Cambodia and Vietnam. Herpetology Notes 5: 5-7.

Ihlow, F., J.E. Dawson, T. Hartmann, and S. Som. 2016. Indotestudo elongata (Blyth 1854) - Elongated Tortoise, Yellow-headed Tortoise, Yellow Tortoise. In: A.G.J. Rhodin, P.C.H. Pritchard, P.P. van Dijk, R.A. Saumure, K.A. Buhlmann, J.B. Iverson, and R.A. Mittermeier (eds.), Conservation Biology of Freshwater Turtles and Tortoises: A Compilation Project of the IUCN/
SSC Tortoise and Freshwater Turtle Specialist Group. Chelonian Research Monographs 5(9): 096.1-14.

Kästle, W., K.R. Rai, and H.H. Schleich. 2013. Field Guide to Amphibians and Reptiles of Nepal. ARCO-Nepal e.V., München, Germany.

Kiesl, L. and H. Schleich. 2016. Amphibians and Reptiles of Nepal. Turtles. A Children's Book. Third edition. ARCO-Nepal e.V., München, Germany.

Rahman, S., K. Platt, I. Das, B.C. Choudhury, M.F. Ahmed, M. Cota, T. McCormack, R.J. Timmins, and S. Singh. 2019. Indotestudo elongata (errata version published in 2019). The IUCN Red List of Threatened Species 2019: e.T10824A152051190. <https://dx.doi.org/10.2305/IUCN.UK.2019-1.RLTS.T10824A152051190.en>.

Rai, T.P. 2017. Conservation of endangered turtles in 'Turtle Rescue and Conservation Center' at Sukhani Martyrs Memorial Park, Jhapa. Journal of Mechi Multiple Campus 6: 81-90.

Rai, T.P. 2019. Reassessment of herpetofauna from Jhapa District, East Nepal. Arco-Nepal Newsletter 19: 9-17.

Schleich, H.H. and W. Kästle (eds.). 2002. Amphibians and Reptiles of Nepal: Biology, Systematics, Field Guide. A.R.G. Gantner Verlag, Ruggell, Liechtenstein.

Sharma, R.C. 1998. Fauna of India and Adjacent Countries. Reptilia Volume I (Testudines and Crocodilians). Zoological Survey of India, Kolkata, India.

Uetz, P., P. Freed, and J. Hoŝek (eds.) 2019. The Reptile Database. <http://www. reptile-database.org>. 